\title{
Rules of the game of doing science
}

Scientific good practice - disinterested, communal, universal - is not 'blobby' idealism, but a social framework to which researchers must conform if they are to prosper. Now, this contract with society is up for renegotiation.

\section{John Ziman}

$\mathrm{N}$ ineteen-forty-two was a pretty awful year. Democracy had its back to the wall. Science was a sinew of war. But this was also the year when it was shown that science and democracy are indissolubly united.

Robert Merton was a whiz-kid professor of sociology at Columbia University, New York. He was an expert on the place of science in society. So he gathered some of his ideas into a little paper on "Science and Society in a Democratic Order". Its appearance, in the first issue of an obscure journal, is the event I celebrate (J. Legal and Political Sociology 1, 115-262; 1942). Not that I - nor, I suspect, many others - read this paper at the time. It didn't come my way until nearly 30 years later, perhaps as an exchanged offprint, perhaps in a collection of the writings of this now famous scholar. By then its title had become "The Normative Structure of Science". As sometimes happens, a conceptual skeleton constructed to stiffen a slightly floppy argument had proved more enduring than its empirical flesh. Merton's X-ray eye had detected the internal social framework that gives science its strength.

In the then sociological fashion, he described science as an "ethos", held together by "norms". Research results are "communal" - they belong to the whole scientific community. They must be "universal" independent of class or creed. They must be presented "disinterestedly", and be subject to "organized skepticism". At first, these sound like blobby ideals, mainly suitable for public panegyrics. But Merton saw them functionally, as the regulatory principles of a way of life. These are the rules of the game of doing science, which every player is forced to obey if she or he is to stay on the field.

The Mertonian norms are not just unattainable personal attitudes. They are embodied in innumerable social conventions and mundane practices. These define and constrain our conduct as scientists. Publish - or perish. Face up to the demands of peer review. Cite generously and meticulously. Reward originality and priority of discovery. Present your work impersonally. Exclude ad hominem jibes. And so on.

These requirements are often irksome. We may sometimes be tempted to keep profitable ideas secret, skimp on measurements, fudge data, pirate the work of others, ignore criticism, boost ourselves or vilify our opponents. But our good name is at stake. Without personal credibility, our research would be disregarded, and jobs would no longer come our way. So we strive to perform as expected, and as we expect of our colleagues. The logic of life forces us to think and act scientifically, until it becomes second nature.

Merton's novel insight was that science he meant 'pure' science, for industrial research and technology work differently is not just the activity of a community of likeminded individuals. It is a distinctive institution, with a distinctive culture. Its everyday practices dovetail into a compelling social framework. This framework supports a 'method', an attitude of mind, a profession, a body of knowledge. He made us realize that science is driven, shaped and honed as much by its internal sociology as by its philosophy or psychology.

In 50 years, the sociology of science has grown into an established academic discipline. Unfortunately, the focus of this discipline has shifted. Sociology seems almost against science as it strives to put it in its place. Well, of course, scientific knowledge is not uniquely true, science is not the only pebble on the social beach, and scientists, like traffic wardens and airline pilots, are ordinary folk too. These are realities that we should all humbly accept.

Yet science remains a peculiar institution, with its own way of doing things. Love it or loathe it, we need to understand just what

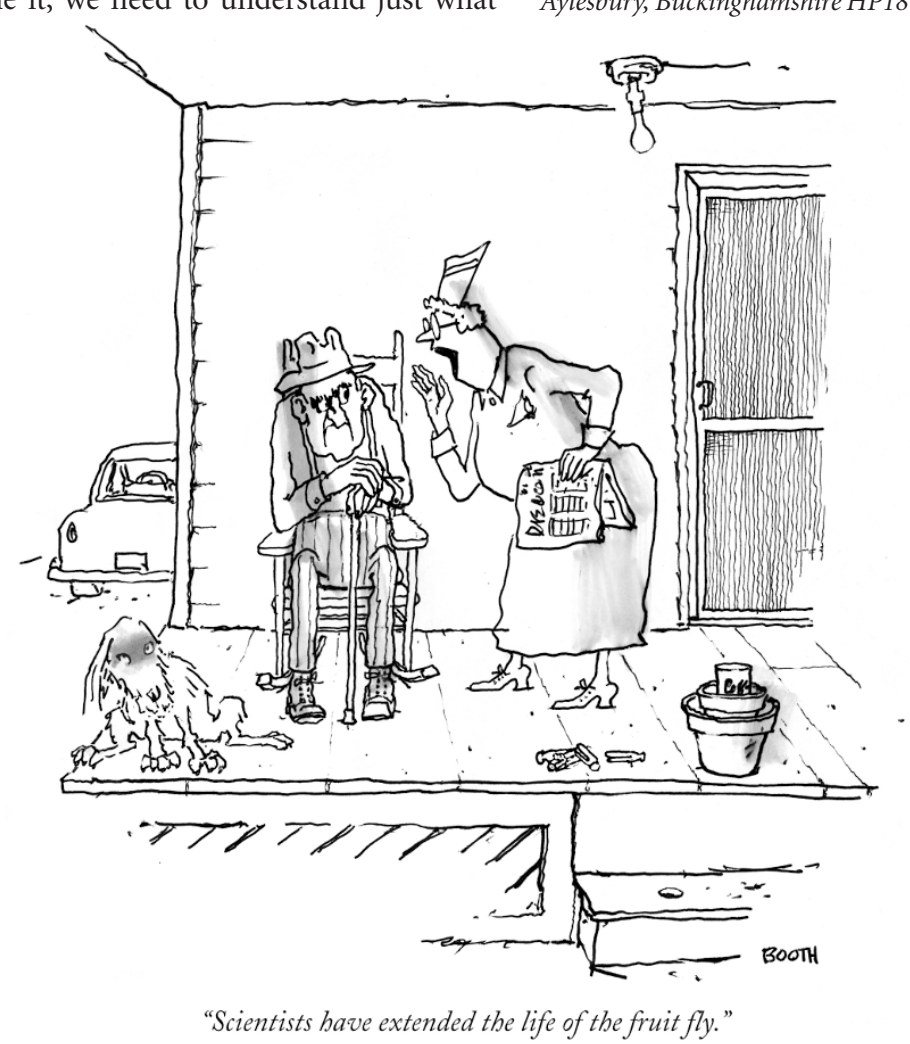

^๑) 1999 Macmillan Magazines Ltd makes it tick. Is extreme specialization, for example, an essential cog in the social machine? What winds the clockwork social imperatives, coordinated curiosity or competitive ambition? How can anybody tell whether it is working properly? Whose hands are on the lever for adjusting its output?

What is more, science is no longer what it was when Merton first wrote about it. The bureaucratic engine of policy is shattering the traditional normative frame. Big science has become a novel way of life, with its own conventions and practices. What price now those noble norms? Tied without tenure into a system of projects and proposals, budgets and assessments, how open, how disinterested, how self-critical, how riskily original can one afford to be?

There is no going back to that world we have lost. Anyway, science has never had it so good as in this past half-century, and is still going great guns. But soon it will be offered a new contract with society. To renegotiate that contract with its eyes open, on even terms, science will need to understand itself much better. That understanding is going to require, not adherence to an obsolete ethos, but a sharp but sympathetic sociological selfanalysis. That is the unfinished business that Merton's little paper began.

John Ziman is at 27 Little London Green, Oakley, Aylesbury, Buckinghamshire HP18 9QL, UK. 